\title{
DETERMINATION OF PERIOD OF VIBRATION OF BUILDINGS WITH OPEN STILT FLOOR AND SHEAR WALLS
}

\author{
Naveen B.S ${ }^{1}$, Parikshith Shetty ${ }^{2}$, Naveen Kumar B.S ${ }^{3}$ \\ ${ }^{1}$ Assistant Professor Dept. of Civil Engineering, RK University, Rajkot, Gujarat, India \\ ${ }^{2}$ Structural Engineer Frames Group of Energy system, Pune, Maharashtra, India \\ ${ }^{3}$ Assistant professor Dept. of civil Engineering, GMIT college, Davanagere, Karnataka, India
}

\begin{abstract}
To estimate the natural period of vibration, codes consign the empirical formula that solely relies on height of the structure. Present dissertation is carried out considering aspects such as building material, type of structure and structural dimensions. The foremost objective of the present systematic study has led to a simplified period-height equation for use in the seismic evaluation of reinforced concrete structures, taking due significance of the existence of stilt floors and shear walls. Current study also highlights the criteria that affects the period of vibration. The period of vibration which has been procured in this study represents the time period of first mode of vibration. This article comprises the seismic response of structures on different types of soil. The parameters considered for the given study are three different types of soil i.e., soft soil, medium soil and hard rock for high seismic zone and different building irregularities as per IS: 1893-2002 for 10, 15, 20 storey buildings. The analytical models for the modulus study are modeled through ETABS.V.9.2. Various parametric studies are carried out to determine the fundamental time period of the structures. These ameliorate formulas to determine the fundamental time period are developed using nonlinear regression analysis through ORIGIN pro software. The generalized equation finally obtained can be used in general form to calculate the time period of structures with open stilt floor and shear walls irrespective of soil types, seismic zone or building height.
\end{abstract}

Keywords- Time period, open stilt floor, Shear walls, Irregularities in buildings, nonlinear regression

\section{INTRODUCTION}

Earthquake Ground Motions (EQGMs) are the most dangerous natural hazards where both economic and life losses occur. Most of the losses are due to building collapses or damages. Earthquake can cause damage not only on account of vibrations which results from them but also due to other chain effects like landslides, floods, fires etc. Therefore, it is very important to design the structures to resist, moderate to severe EQGMs depending on its site location and importance of the structure. If the existing building is not designed for earthquake then its retrofitting becomes important. Seismic requirements were not included in building codes as early as those for wind, although some experimentation had taken place in Europe and even more in Japan, which suffered from frequent seismic activity. Some of the early approaches yielded little result, but that did not stop curious minds from experimenting. Mindful, that the force is equal to mass times acceleration, the regulations there started to require that all buildings should be designed for a static horizontal force equal to $10 \%$ of their weight. The seismic analysis of engineering structures is often based on the assumption that the foundation corresponds to a rigid block, which is subjected to a horizontal unidirectional acceleration which constitutes an adequate representation of the physical situation in case of average size structure founded on a sound rock. Under such condition it has been verified that the free field motion at the rock surface, i.e., the motion that would occur without the structure, is barely influenced by its presence. The hypothesis loses its validity when the structure is deposited on soil deposits, since the motion at the soil surface, without the structure may be significantly altered by the presence of the structure. Thus the determination of the natural period of vibration of a reinforced concrete structure is an indispensable $\mathrm{mechanism}$ in earthquake design and evaluation.

\section{IRREGULAR BUILDINGS}

The buildings can be broadly categorized as regular and irregular buildings. An irregular building can be defined as a building that lacks symmetry and has discontinuity in geometry, mass or load resisting elements. The structural irregularities can be broadly categorized as horizontal and vertical irregularity. The structural irregularities affect the natural vibration of a building. Buildings irregularities considered in the present article are diaphragm irregularity, mass irregularity, non parallel irregularity, offset irregularity, re-entrant corner irregularity as per IS 1893:2002 (BIS, 2002),

\section{OPEN STILT FLOOR}

The essential distinction between a soft storey and a weak storey is that while a soft storey is classified based on stiffness or simply the relative resistance to lateral deformation or storey drift, the weak storey qualifies on the basis of strength in terms of force resistance (statics) or energy capacity (dynamics). 
A soft storey is characterized by vertical discontinuity in stiffness. When an individual storey in a building (often the ground level storey) is made taller and more open in construction, it is called a soft storey. It is also sometimes referred to as flexible storey. The soft storey can-and sometimes does- occur at an upper level. However, it is more common at the ground level between a rigid foundation system and a relatively stiffer upper level system. This form of construction is quite common in residential and commercial buildings. Any storey, for which the lateral stiffness is less than 60 per cent of that of the storey immediately above, or less than 70 per cent of the combined stiffness of the three storeys above, is classified as a soft storey. Buildings with a soft storey at the ground level having open spaces for parking are known as stilt buildings or buildings with open stilt floor.

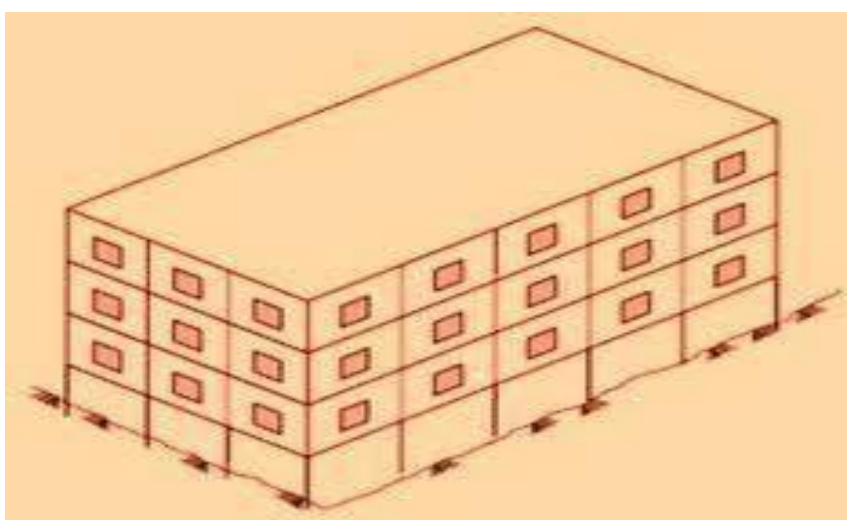

Fig 1.1: Image showing a building with open stilt floor.

\section{SHEAR WALLS}

Bearing wall systems consist of vertical load carrying walls located along exterior wall lines and at interior locations as necessary. Many of these bearing walls are also used to resist lateral forces and are then called shear walls. Bearing wall systems do not contain complete vertical load-carrying space frames but may use some columns to support floor and roof vertical loads. Shear walls resist two types of forces: shear forces and uplift forces. Connections to the structure above transfer horizontal forces to the shear wall. This transfer creates shear forces throughout the height of the wall between the top and bottom shear wall connections.

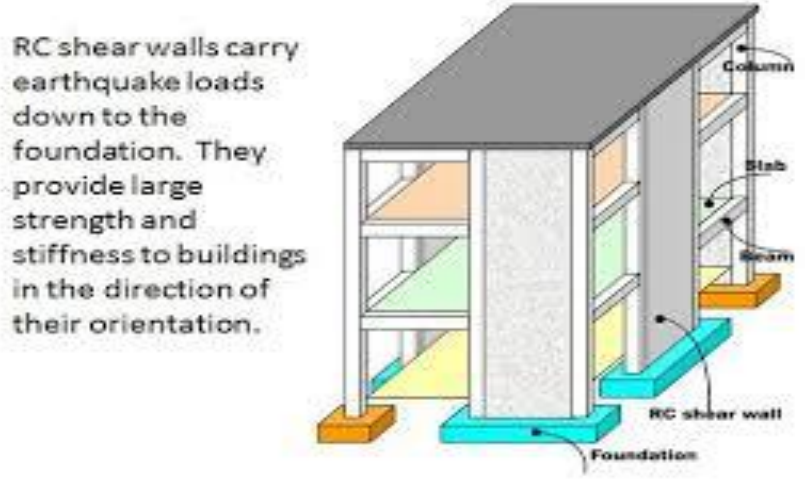

Fig 1.2: Image showing shear wall in reinforced concrete building

\section{MODELING CONSIDERATIONS}

The location of the joints and elements is critical in determining the accuracy of the structural model. Some of the factors that needs to be considered when defining the elements, and hence the joints, for the structure are:

1. The number of elements should be sufficient to describe the geometry of the structure. For straight lines and edges, one element is adequate. For curves and curved surfaces, one element should be used for every arc of $15^{\circ}$ or less.

2. Element boundaries, and hence joints, should be located at points, lines, and surfaces of discontinuity:

- $\quad$ Structural boundaries, e.g., corners and edges

- Changes in material properties

- Changes in thickness and other geometric properties, support points(Restraints and springs)

- Points of application of concentrated loads, except that Frame elements may have concentrated loads applied within their spans

3. In regions having large stress gradients, i.e., where the stresses are chang ing rapidly, an Area- or Solid-element mesh should be refined using small elements and closely- spaced joints. This may require changing the mesh after one or more preliminary analyses.

4. More than one element should be used to model the length of any span for which dynamic behavior is important. This is required because the mass is always lumped at the joints, even if it is contributed by the elements.

\section{SOIL PARAMETERS CONSIDERED IN THE STUDY}

The different soil types considered in this study are varied as per the soil parameters such as dynamic shear modulus and poisons ratio ( $\square \square$ ).The type of soil considered is soft soil, medium sand(compact and dry) and hard rock (stiff) based on dynamic shear modulus.

\begin{tabular}{|l|l|l|}
\hline $\begin{array}{l}\text { Properties of soil types } \\
\text { considered in this study. }\end{array}$ & \multicolumn{2}{|l|}{} \\
\hline Soil type 1(hard soil) & & \\
\hline Poisson ratio $\mu$ & 0.5 & \\
\hline Mass Density $\rho$ & 2000 & $\mathrm{Kg} / \mathrm{m} 3$ \\
\hline Shear wave velocity $v$ & 1500 & $\mathrm{~m} / \mathrm{s}$ \\
\hline Shear modulus G & 4500000 & $\mathrm{Kn} / \mathrm{m} 2$ \\
\hline $\begin{array}{l}\text { Safe Bearing Capacity } \\
\text { (ref:Bowles) }\end{array}$ & 3240 & $\mathrm{Kn} / \mathrm{m} 2$ \\
\hline Soil type 2(medium soil) & & \\
\hline Poisson ratio $\mu$ & 0.5 & \\
\hline
\end{tabular}




\begin{tabular}{|l|l|l|}
\hline Mass Density $\rho$ & 1700 & $\mathrm{Kg} / \mathrm{m} 3$ \\
\hline Shear wave velocity $v$ & 800 & $\mathrm{~m} / \mathrm{s}$ \\
\hline Shear modulus G & 1088000 & $\mathrm{Kn} / \mathrm{m} 2$ \\
\hline $\begin{array}{l}\text { Safe Bearing Capacity } \\
\text { (ref:Bowles) }\end{array}$ & 245 & $\mathrm{Kn} / \mathrm{m} 2$ \\
\hline Soil type 3(soft soil) & $\mu$ & $\mathrm{Kg} / \mathrm{m} 3$ \\
\hline Poisson ratio & 0.5 & $\mathrm{~m} / \mathrm{s}$ \\
\hline Mass Density $\rho$ & 1500 & $\mathrm{Kn} / \mathrm{m} 2$ \\
\hline Shear wave velocity $v$ & 200 & $\mathrm{Kn} / \mathrm{m} 2$ \\
\hline Shear modulus G & 60000 & \\
\hline $\begin{array}{l}\text { Safe Bearing Capacity } \\
\text { (ref:Bowles) }\end{array}$ & 50 & \\
\hline
\end{tabular}

7. DESIGN DATA CONSIDERED FOR ALL THE

\section{BUILDINGS}

Table 1.1: Input data of all the building models

\begin{tabular}{|l|l|}
\hline No. of storey & $10,15,20$ \\
\hline Storey height & $3.0 \mathrm{~m}$ \\
\hline Seismic zone & $\mathrm{V}$ \\
\hline Material Properties \\
\hline Grade of concrete & M25(SLABS), \\
& M30, M35,M40(columns) \\
\hline
\end{tabular}
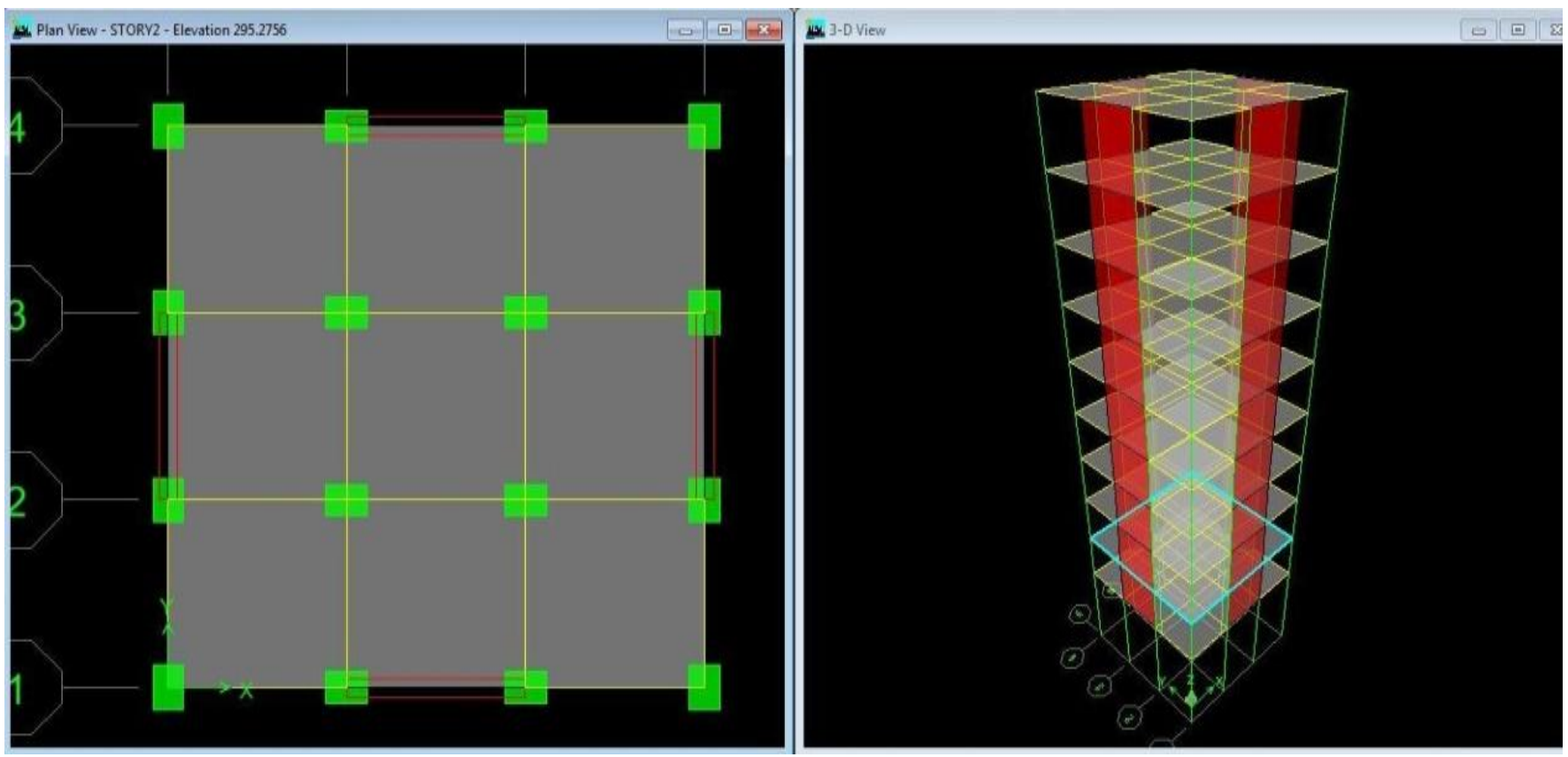

Fig 1.3 ETABS model screen shot of a regular 10 storied building

\begin{tabular}{|l|l|}
\hline Grade of steel & Fe 415 \\
\hline $\begin{array}{l}\text { Density of reinforced } \\
\text { concrete }\end{array}$ & $25 \mathrm{kN} / \mathrm{m}^{3}$ \\
\hline Member Properties \\
\hline $\mathbf{1 0}$ Storey & $0.2 \mathrm{~m}$ \\
\hline Slab & $0.4 \mathrm{mx} 0.6 \mathrm{~m}$ \\
\hline Column & $0.3 \mathrm{~m}$ \\
\hline Shear wall & \\
\hline 15 Storey & $0.2 \mathrm{~m}$ \\
\hline Slab & $0.4 \mathrm{mx} 0.6 \mathrm{~m}, .05 \mathrm{mx} 0.7 \mathrm{~m}$ \\
\hline Column & $0.3 \mathrm{~m}$ \\
\hline Shear wall & \\
\hline 20 Storey & $0.2 \mathrm{~m}$ \\
\hline Slab & $0.4 \mathrm{mx} 0.6 \mathrm{~m}, 0.5 \mathrm{mx} 0.7 \mathrm{~m}, 0.6 \mathrm{x} 0.8 \mathrm{~m}$ \\
\hline Column & $0.3 \mathrm{~m}$ \\
\hline Shear wall & Roof- $1.5 \mathrm{kN} / \mathrm{m}^{2}$, floor $-3.0 \mathrm{kN} / \mathrm{m}^{2}$ \\
\hline Live & \\
\hline
\end{tabular}

\section{PRESENT ANALYSIS}

The study includes the seismic response of regular and irregular and soil flexibility using the Winkler's soil model. The parameters considered for the present study are three different type of soil for high seismic zone and building irregularities like plan irregularity and vertical irregularities such as mass irregularity, non parallel irregularity, offset irregularity, stiffness irregularity and re-entrant corners irregularity as per IS:1893-2002 for 10, 15, 20 storey buildings. 

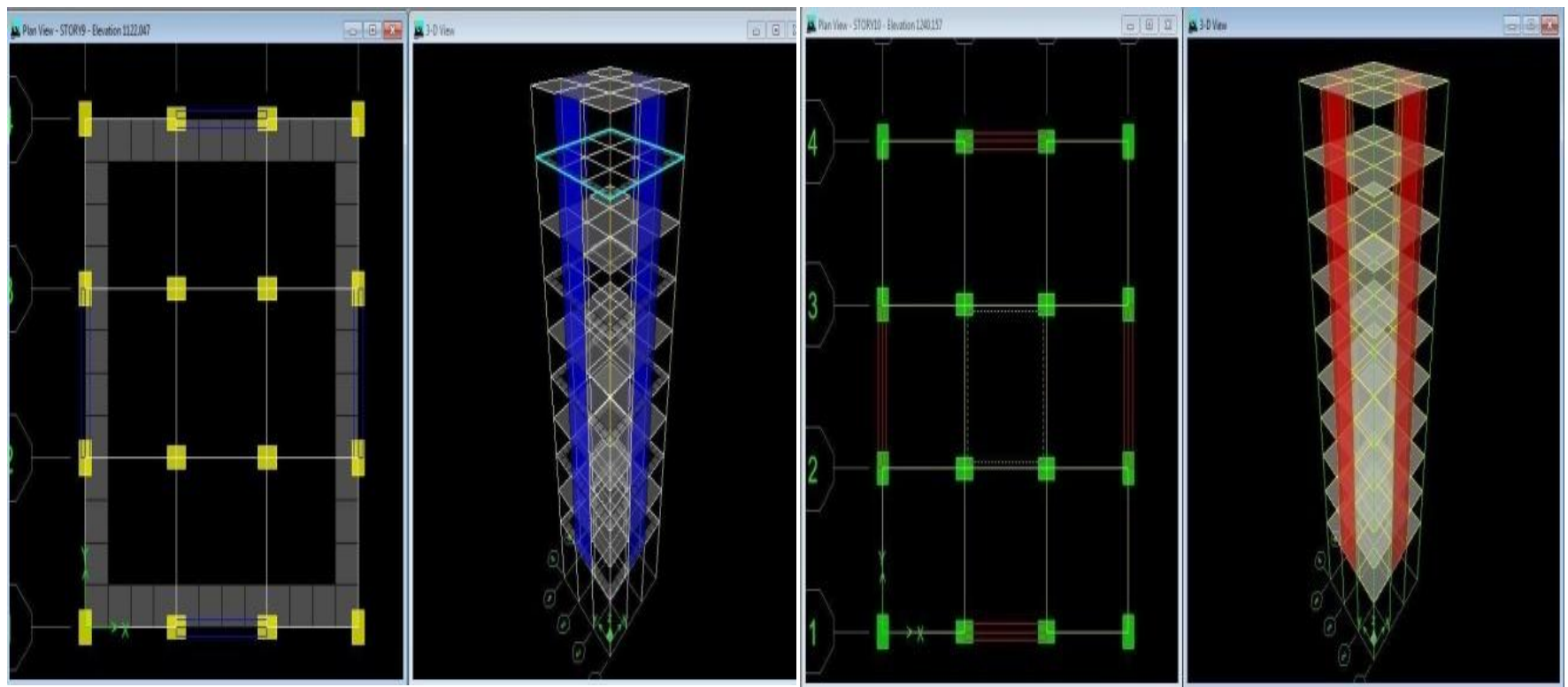

Fig 1.4 ETABS model screen shot of Diaphragm irregular and mass irregularity 10 storied building

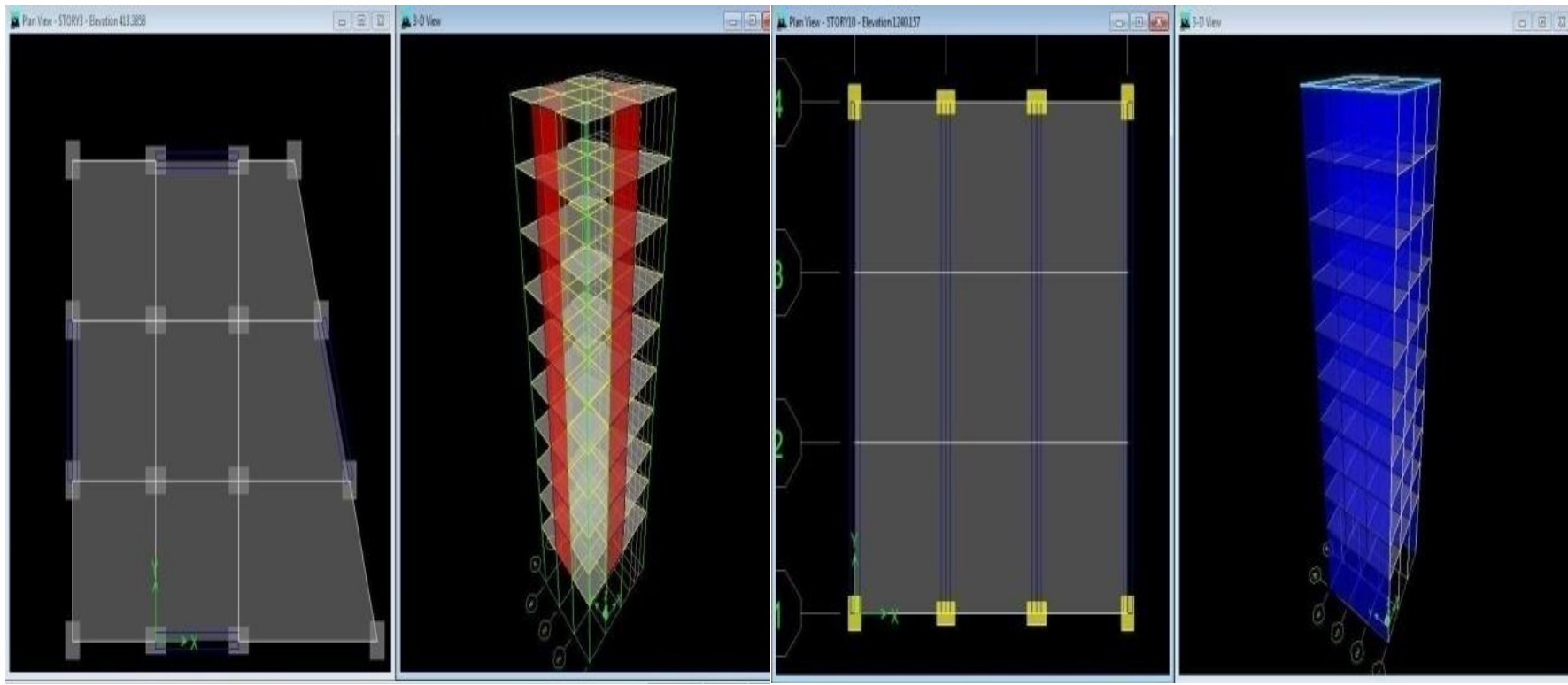

Fig 1.5 ETABS model screen shot of Non parallel irregularity and offset irregularity 10 storied building
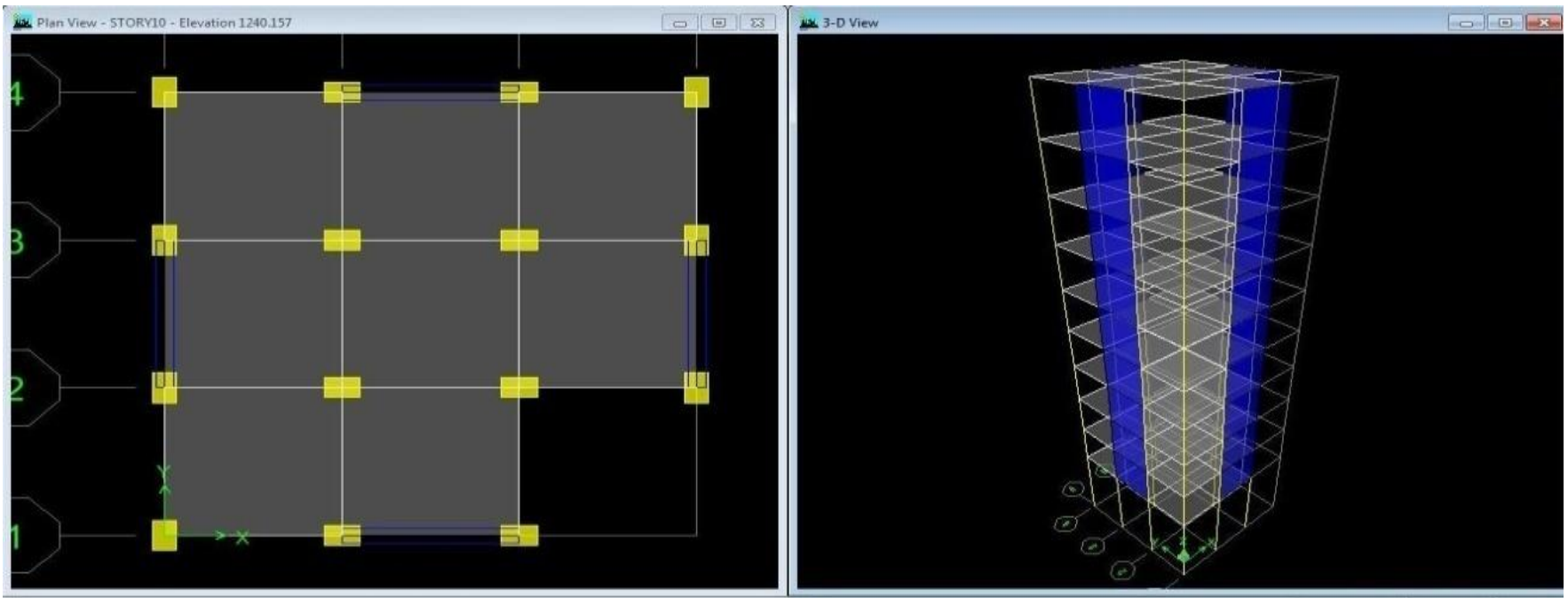

Fig 1.6 ETABS model screen shot of re-entrant corners irregularity 10 storied building 


\subsection{Fundamental Time Period for Regular Buildings}

Table 1.2 Details of fundamental time period for regular buildings

\begin{tabular}{|l|l|l|l|l|}
\hline Type of building & Number of stories & \multicolumn{3}{|l|}{ Fundamental time periods in seconds for soil type } \\
\hline \multirow{3}{*}{ Regular } & & $\mathrm{S} 1$ & $\mathrm{~S} 2$ & $\mathrm{~S} 3$ \\
\cline { 2 - 5 } & 10 & 0.930 & 0.934 & 0.992 \\
\cline { 2 - 5 } & 15 & 1.430 & 1.454 & 1.536 \\
\cline { 2 - 5 } & 20 & 1.838 & 1.899 & 1.996 \\
\hline
\end{tabular}

\subsection{Fundamental Time Period for Diaphragm Irregularity Buildings}

Table 1.3 Details of fundamental time period for diaphragm irregularity buildings

\begin{tabular}{|l|l|l|l|l|}
\hline Type of building & Number of stories & \multicolumn{4}{|l|}{ Fundamental time periods in seconds } \\
& & for soil type \\
\hline \multirow{3}{*}{ Diaphragm irregularity } & & $\mathrm{S} 1$ & $\mathrm{~S} 2$ & $\mathrm{~S} 3$ \\
\cline { 2 - 5 } & 10 & 0.894 & 0.897 & 0.951 \\
\cline { 2 - 5 } & 15 & 1.243 & 1.249 & 1.341 \\
\cline { 2 - 5 } & 20 & 1.787 & 1.795 & 1.913 \\
\hline
\end{tabular}

\subsection{Fundamental Time Period For Mass Irregularity Buildings}

Table 1.4 Details of fundamental time period for mass irregularity buildings.

\begin{tabular}{|c|c|c|c|c|}
\hline \multirow[t]{2}{*}{ Type of building } & \multirow[t]{2}{*}{$\begin{array}{l}\text { Number } \\
\text { stories }\end{array}$} & \multicolumn{3}{|c|}{$\begin{array}{l}\text { of Fundamental time periods in } \\
\text { seconds } \\
\text { for soil Type }\end{array}$} \\
\hline & & $\mathrm{S} 1$ & $\mathrm{~S} 2$ & S3 \\
\hline \multirow{3}{*}{ Mas irregularity } & 10 & 0.932 & 0.935 & 0.993 \\
\hline & 15 & 1.449 & 1.455 & 1.536 \\
\hline & 20 & 1.891 & 1.897 & 2.010 \\
\hline
\end{tabular}

\subsection{Fundamental Time Period for Non Parallel Irregularity Buildings}

Table 1.5 Details of fundamental time period for nonparallel irregularity buildings

\begin{tabular}{|c|c|c|c|c|}
\hline Type of buildings & Number of stories & \multicolumn{3}{|c|}{$\begin{array}{l}\text { Fundamental time periods in seconds } \\
\text { for soil Type }\end{array}$} \\
\hline \multirow{4}{*}{ Non parallel irregularity } & & S1 & $\mathrm{S} 2$ & S3 \\
\hline & 10 & 0.977 & 0.980 & 1.034 \\
\hline & 15 & 1.525 & 1.526 & 1.602 \\
\hline & 20 & 1.922 & 1.916 & 2.042 \\
\hline
\end{tabular}

\subsection{Fundamental Time Period for Offset Irregularity Buildings}

Table 1.6 Details of fundamental time period for offset irregularity building

\begin{tabular}{|l|l|l|l|l|}
\hline Type of buildings & Number of stories & \multicolumn{4}{l|}{$\begin{array}{l}\text { Fundamental time periods in seconds } \\
\text { for soil Type }\end{array}$} \\
\hline \multirow{3}{*}{ Offset irregularity } & $\mathrm{S} 1$ & $\mathrm{~S} 2$ & $\mathrm{~S} 3$ \\
\cline { 2 - 5 } & 10 & 1.291 & 1.292 & 1.310 \\
\cline { 2 - 5 } & 15 & 1.889 & 1.890 & 1.578 \\
\cline { 2 - 5 } & 20 & 2.224 & 2.227 & 2.293 \\
\hline
\end{tabular}




\subsection{Fundamental Time Period for Re-Entrant Corner Irregularity Buildings}

Table 1.7 Details of fundamental time period for re-entrant corner irregularity building

\begin{tabular}{|l|l|l|l|l|}
\hline Type of buildings & Number of stories & \multicolumn{3}{|l|}{$\begin{array}{l}\text { Fundamental time periods in seconds } \\
\text { for soil tvpe }\end{array}$} \\
\hline \multirow{3}{*}{ Re-entrant irregularity } & S1 & S2 & S3 \\
\cline { 2 - 5 } & 10 & 0.939 & 0.943 & 1.006 \\
\cline { 2 - 5 } & 15 & 1.417 & 1.422 & 1.386 \\
\cline { 2 - 5 } & 20 & 1.928 & 1.936 & 2.068 \\
\hline
\end{tabular}

\subsection{Fundamental Natural Time Period for Hard Rock (S1)}

Table 1.8 Details of fundamental time period for hard rock (S1) combine of all irregularity buildings

\begin{tabular}{|l|l|l|l|}
\hline Type of buildings & \multicolumn{3}{l|}{ combine of all irregularities } \\
\hline Number of stories & 10 & 15 & 20 \\
\hline \multirow{5}{*}{ Fundamental time period in seconds } & 0.930 & 1.430 & 1.838 \\
\cline { 2 - 5 } & 0.894 & 1.243 & 1.787 \\
\cline { 2 - 5 } & 0.932 & 1.449 & 1.891 \\
\cline { 2 - 5 } & 0.997 & 1.525 & 1.922 \\
\cline { 2 - 5 } & 1.291 & 1.889 & 2.224 \\
\cline { 2 - 4 } & 0.939 & 1.407 & 1.928 \\
\hline
\end{tabular}

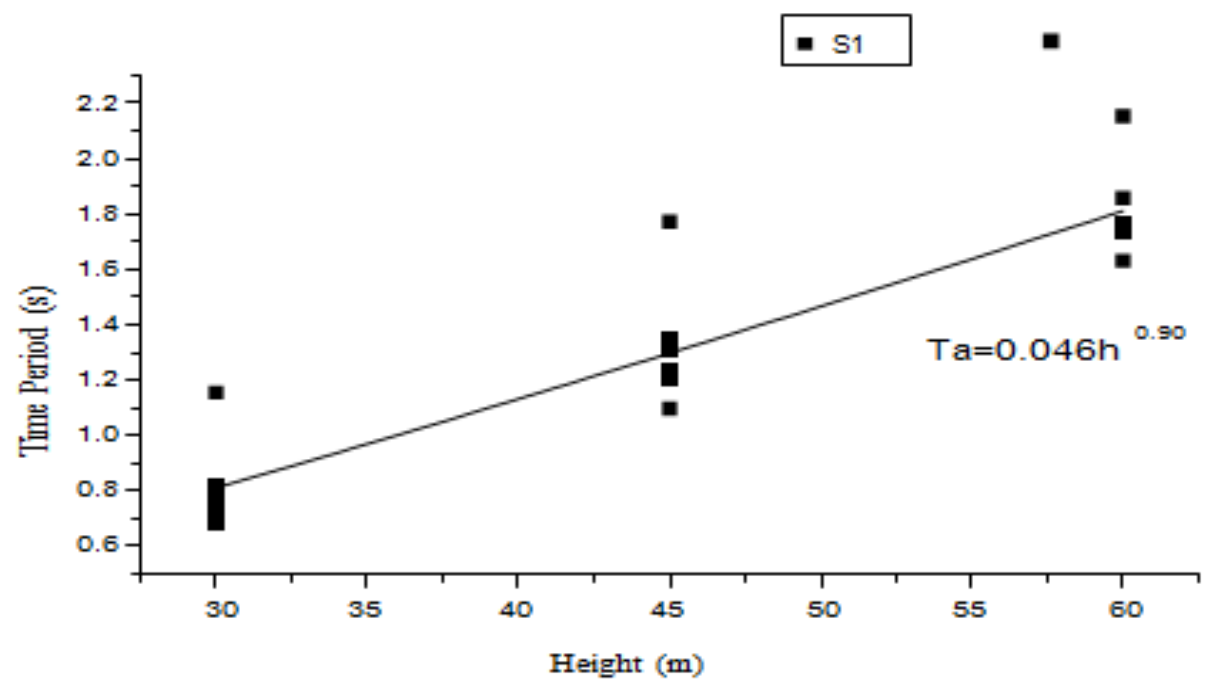

Graph1.1: period -height relationships for hard rock (S1) combine of all irregularity building

Fundamental natural time periods can be seen in the graph 1.1 for 10, 15 and 20 storey buildings designed for all type of structural irregularities. The fundamental period is increasing as the number of storeys have been increased which we can see in above table $\mathbf{1 . 8}$ and the approximate fundamental natural period of vibration (Ta) of a open stilt floor with shear walls building for hard rock S1 may be estimated by the analytical expression generated below:

$$
T_{a}=0.046 h^{0.9}
$$

Where $\mathrm{h}=$ Height of building in $\mathrm{m}$.

\subsection{Fundamental Natural Time Period for Medium} Soil (S2)

Table 1.9 Details of fundamental time period for medium soil (S2) combine of all irregularity buildings

\begin{tabular}{|l|l|l|l|}
\hline Type of buildings & \multicolumn{3}{|l|}{$\begin{array}{l}\text { combine of } \\
\text { irregularities }\end{array}$} \\
\hline Number of stories & 10 & 15 & 20 \\
\hline \begin{tabular}{l} 
Fundamental $\begin{array}{l}\text { all } \\
\text { period in seconds }\end{array}$ \\
\cline { 2 - 4 }
\end{tabular} & 0.934 & 1.454 & 1.899 \\
\cline { 2 - 4 } & 0.897 & 1.249 & 1.795 \\
\cline { 2 - 4 } & 0.935 & 1.455 & 1.897 \\
\cline { 2 - 4 } & 0.980 & 1.526 & 1.916 \\
\cline { 2 - 4 } & 1.292 & 1.890 & 2.227 \\
\cline { 2 - 4 } & 0.943 & 1.422 & 1.936 \\
\hline
\end{tabular}




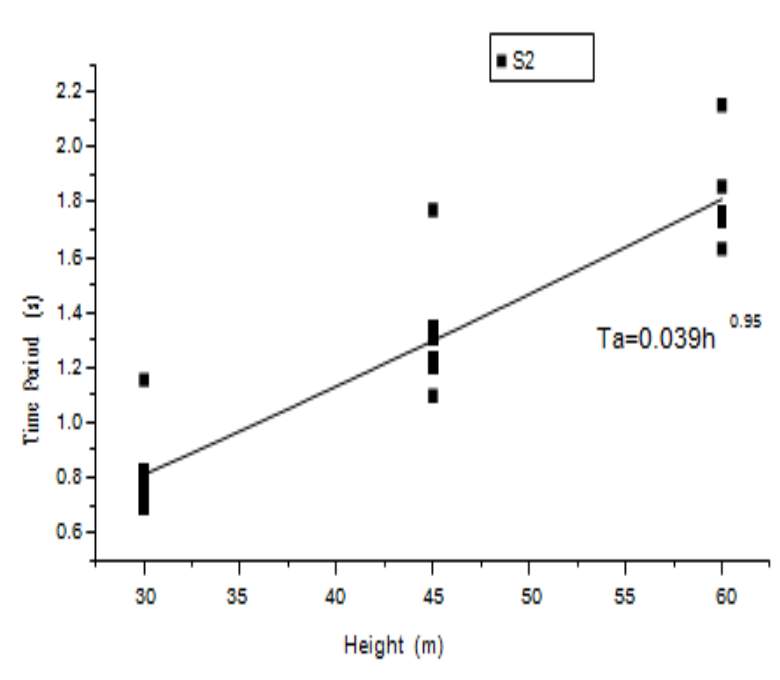

Graph1.2: period -height relationships for medium soil (S2) combine of all irregularity building

Fundamental natural time periods can be seen in the graph 1.2 for 10, 15 and 20 storey buildings designed for all type of structural irregularities. The fundamental period is increasing as the number of storeys have been increased which can be seen in above table $\mathbf{1 . 9}$ and the approximate fundamental natural period of vibration (Ta) of a open stilt floor with shear walls building for medium soil S2 may be estimated by the analytical expression generated below:

$$
T_{a}=0.039 h^{0.95}
$$

Where $\mathrm{h}=$ Height of building, in $\mathrm{m}$.

\subsection{Fundamental Natural Time Period for Soft Soil}

(S3)

Table 1.10 Details of fundamental time period for soft soil (S3) combine of all irregularity buildings

\begin{tabular}{|l|l|l|l|}
\hline Type of buildings & \multicolumn{3}{|l|}{ combine of } \\
& irregularities \\
\hline Number of stories & 10 & 15 & 20 \\
\hline \multirow{3}{*}{} & 0.992 & 1.536 & 1.996 \\
\hline & 0.951 & 1.341 & 1.913 \\
\hline
\end{tabular}

\begin{tabular}{|l|l|l|l|}
\hline $\begin{array}{l}\text { Fundamental time period } \\
\text { in seconds }\end{array}$ & 0.993 & 1.536 & 2.010 \\
\hline 1.034 & 1.602 & 2.042 \\
\hline 1.310 & 1.578 & 2.293 \\
\hline 1.006 & 1.386 & 2.068 \\
\hline
\end{tabular}

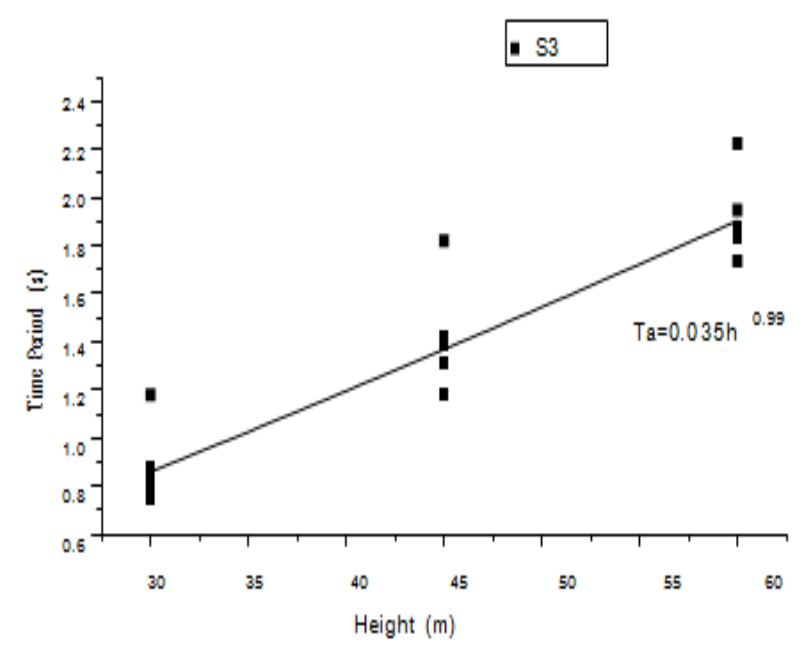

Graph1.3: period -height relationships for soft soil (S3) combine of all irregularity building

Fundamental natural time periods can be seen in the graph 1.3 for 10, 15 and 20 storey buildings designed for all type of structural irregularities. The fundamental period is increasing as the number of storeys have been increased which can be seen in above table $\mathbf{1 . 1 0}$ and the approximate fundamental natural period of vibration (Ta) of a open stilt floor with shear walls building for soft soil S3 may be estimated by the analytical expression generated below:

$$
T_{a}=0.035 h
$$

Where $\mathrm{h}=$ Height of building, in $\mathrm{m}$.

8.10 Details of Fundamental Time Periods of Combined Irregularities of Buildings for All Type Soils

Table 1.3: Details of fundamental time period of all types of buildings and soil

\begin{tabular}{|l|l|l|l|l|}
\hline \multirow{2}{*}{ Type of buildings } & Number of stories & \multicolumn{3}{|l|}{ Fundamental time periods in seconds } \\
& for soil type & \multicolumn{3}{l|}{} \\
\hline \multirow{5}{*}{ Diaphragm irregularity } & & $\mathbf{S 1}$ & $\mathbf{S 2}$ & $\mathbf{S 3}$ \\
\cline { 2 - 6 } & $\mathbf{1 0}$ & 0.894 & 0.897 & 0.951 \\
\cline { 2 - 6 } & $\mathbf{1 5}$ & 1.243 & 1.249 & 1.341 \\
\cline { 2 - 6 } & $\mathbf{2 0}$ & 1.787 & 1.795 & 1.913 \\
\hline
\end{tabular}




\begin{tabular}{|l|l|l|l|l|}
\hline \multirow{5}{*}{ Mass irregularity } & $\mathbf{1 0}$ & 0.932 & 0.935 & 0.993 \\
\cline { 2 - 6 } & $\mathbf{1 5}$ & 1.449 & 1.455 & 1.536 \\
\cline { 2 - 6 } Non parallel irregularity & $\mathbf{2 0}$ & 1.891 & 1.897 & 2.010 \\
\hline \multirow{5}{*}{ Offset irregularity } & $\mathbf{1 0}$ & 0.977 & 0.980 & 1.034 \\
\cline { 2 - 6 } & $\mathbf{2 0}$ & 1.525 & 1.526 & 1.602 \\
\hline \multirow{5}{*}{ Re-entrant irregularity } & $\mathbf{1 0}$ & 1.922 & 1.916 & 2.042 \\
\cline { 2 - 6 } & $\mathbf{1 5}$ & 1.291 & 1.292 & 1.310 \\
\cline { 2 - 6 } & $\mathbf{2 0}$ & 1.889 & 1.890 & 1.578 \\
\hline \multirow{3}{*}{ Regular building } & $\mathbf{1 0}$ & 2.224 & 2.227 & 2.293 \\
\cline { 2 - 6 } & $\mathbf{1 5}$ & 0.939 & 0.943 & 1.006 \\
\hline & $\mathbf{2 0}$ & 1.417 & 1.422 & 1.386 \\
\hline & $\mathbf{1 5}$ & 1.928 & 1.936 & 2.068 \\
\cline { 2 - 6 } & $\mathbf{2 0}$ & 0.930 & 0.934 & 0.992 \\
\hline
\end{tabular}

NOTE: The notations used below are as follows

$\mathrm{S}_{1}=$ Hard soil, $\mathrm{S}_{2}=$ Medium soil, $\mathrm{S}_{3}=$ Soft soil

\section{GENERALISED FUNDAMENTAL TIME PERIOD EQUATION}

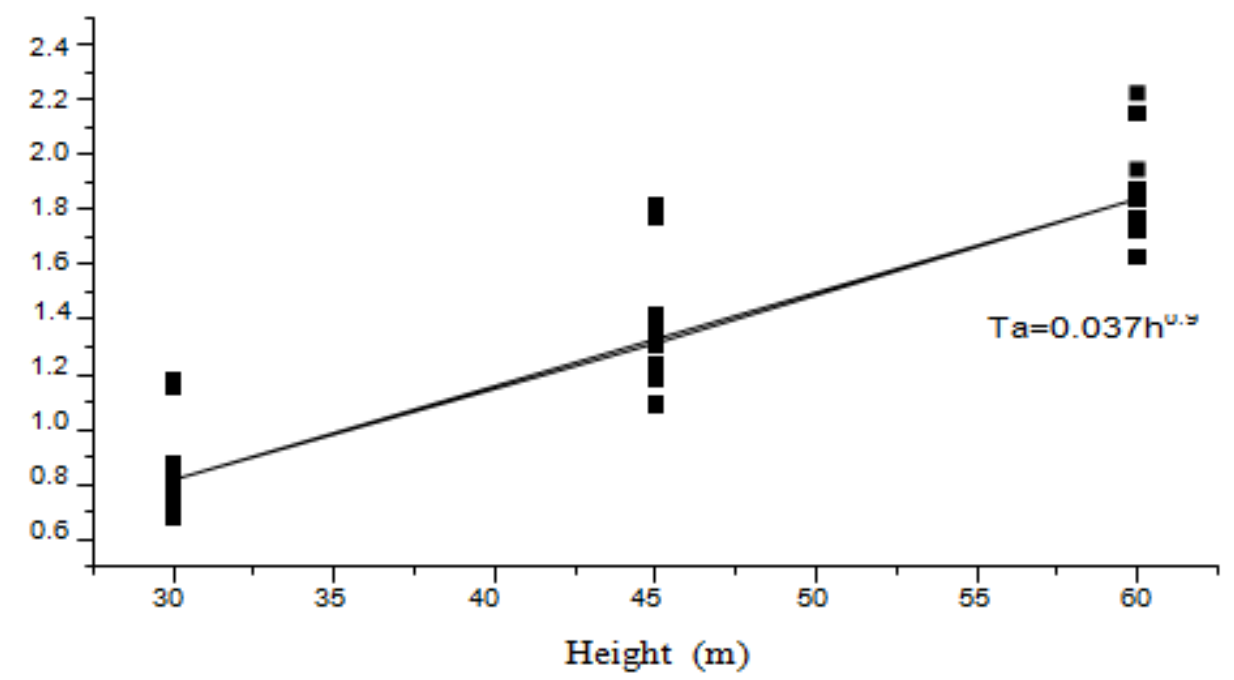

Graph 1.4: Showing Period-Height relationship of all buildings derived from nonlinear regression analysis

It is seen in the graph $\mathbf{1 . 4}$ the generalized time period equation for 10, 15 and 20 storey buildings designed for all type of irregularity building.The fundamental natural period of vibration $(\mathrm{Ta})$ in seconds, of a open stilt floor with shear walls building may be estimated by the analytical expression:

$$
T_{a}=0.037 h
$$

Where,

$\mathrm{T}_{\mathrm{a}}=$ Natural time period of structure in 'Seconds' \& $\mathrm{h}=$ Height of building, in $\mathrm{m}$

These improved formulas for estimating the fundamental time periods of Reinforced concrete buildings with open stilt floor and shear walls are developed using nonlinear regression analysis of the generated time period data of the models modeled in Etabs. 
Table 1.4: Comparison between developed time period formula and fundamental time period formula from code IS: $1893-2002$

\begin{tabular}{|c|c|c|c|c|c|}
\hline \multirow{2}{*}{$\begin{array}{l}\text { IS; } 1893-2002 \text { code } \\
\text { formula for time period }\end{array}$} & \multirow{2}{*}{$\begin{array}{l}\text { New formula for time } \\
\text { period from the present } \\
\text { study }\end{array}$} & \multirow{2}{*}{ Type of soil } & \multirow{2}{*}{$\begin{array}{l}\text { Story } \\
(\mathbf{m})\end{array}$} & \multicolumn{2}{|c|}{$\begin{array}{l}\text { Spectral acceleration co efficient } \\
(\mathrm{Sa} / \mathrm{g})\end{array}$} \\
\hline & & & & From code formula & $\begin{array}{ll}\text { From } & \text { new } \\
\text { formula }\end{array}$ \\
\hline \multirow{9}{*}{$T_{a}=0.075 h^{0.75}$} & \multirow{9}{*}{$T_{a}=0.037 h^{0.97}$} & \multirow{3}{*}{ Soil 1} & 30 & 1.0401 & 0.9976 \\
\hline & & & 45 & 0.7674 & 0.6732 \\
\hline & & & 60 & 0.6185 & 0.5093 \\
\hline & & \multirow{3}{*}{ Soil 2} & 30 & 1.4146 & 1.3568 \\
\hline & & & 45 & 1.0436 & 0.9156 \\
\hline & & & 60 & 0.8411 & 0.6926 \\
\hline & & \multirow{3}{*}{ Soil 3} & 30 & 1.737 & 1.6712 \\
\hline & & & 45 & 1.2815 & 1.1231 \\
\hline & & & 60 & 1.0328 & 0.8553 \\
\hline
\end{tabular}

\section{CONCLUSION}

The dissertation presented here in has led to a simplified period-height based equation for the buildings with open stilt floor and shear walls by considering effect of soil flexibility with various soil types, building irregularities and high seismic zones. From the study, following general conclusions can be drawn,

$>$ The natural time period of a particular structure increases as the Stiffness of soil decreases.

$>$ As stiffness of the structure increases the fundamental time period of a structure decreases.

$>$ The fundamental time period of a structure with diaphragm irregularity decreases as compared to time period of regular building.

$>$ The fundamental time period of a structure with mass irregularity increases as compared to time period of regular building.

$>\quad$ The fundamental time period of a structure with non-parallel irregularity increases as compared to time period of regular building.

$>$ The fundamental time period of a structure with offset irregularity increases as compared to time period of regular building.

$>$ The fundamental time period of a structure with reentrant corners irregularity increases as compared to time period of regular building

The present study has led to a simplified fundamental natural time period formula for buildings with open stilt floor and shear walls. This can be used to perform seismic analysis (Equivalent static) in similar lines as that in IS: 1893-2002 codal provisions.
The equation formulated from the present study is:

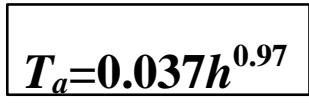

Where,

$\mathrm{T}_{\mathrm{a}}=$ Natural time period of structure in 'Seconds' \& $\mathrm{h}=$ Height of the building in ' $\mathrm{m}$ '

Based on the present study, we can conclude that the new formulation for time period calculation of buildings with open stilt floor and shear walls underestimates the spectral accelerations resulting in smaller seismic forces when compared to the current codal provisions. Based on above findings can conclude that natural time period of a structure is not dependent only on the height of the structure but also depend on the other features such as geometrical features of the structure, soil types and building material. This indicates that the present formula can be used directly for buildings with open stilt floor and shear walls for performing equivalent static seismic analysis.

\section{SCOPE OF FUTURE WORK}

1. Study on these buildings considering the effect of openings in brick in fills can be performed.

2. Study on these buildings can be performed using Time history analysis and push over analysis.

3. Study on these buildings considering 3-D continuum model of soil, structure and foundation can be performed. 


\section{REFERENCES}

[1] Anestis S. Velestos "Seismic Interaction Of Structures and Soils: Stochastic Approach", (1989) Vol. 115, No 4, April, 1989. CASCE, ISSN 07339445/89/0004-0935

[2] Chopra, A.K (1997) "Period Formulas for MomentResisting Frame Buildings, Journal of Structural Engineering", ASCE 123, n ${ }^{\mathrm{O}} 11,1454-1451$.

[3] Chopra, A.K. and Goel, R.K.(2000), "Building Period Formulas for Estimating Seismic

Displacements", Earthquake Spectra, 16, n ${ }^{\circ} 2,533-$ 536.

[4] Dhiman Basu and Sudhir K. Jain "Seismic Analysis of Asymmetric Buildings with Flexible Floor Diaphragms", Vol. 130, No. 8, August 1, 2004. CASCE, ISSN 0733-9445/2004/8-1169-1176

[5] Helen Crowley and Rui Pinho (2006) "Simplified Equations for Estimating the Period of Vibration of Existing Buildings, Proceedings of first European Conference of Earthquake Engineering and Seismology", Geneva, paper n ${ }^{0} 1122$.

[6] Sharany Haque and Khan Mahmud Amanat "Strength and drift demand of columns of RC framed buildings with soft ground story" Journal of Civil Engineering (IEB), 37 (2) (2009) 99-110

[7] Ying Zhou and Xilin Lu "Seismic Performance Evaluation of An Irregular High- Rise Building" Paper No. 099, $4^{\text {th }}$ International Conference on Earthquake Engineering Taipei, Taiwan, October 2006

[8] Yong Lu"Comparative Study of Seismic Behavior of Multi story Reinforced Concrete Framed Structures" Vol. 128, No. 2, February 1, 2002. CASCE, ISSN 0733-9445/2002/2-169-178

[9] S. K Duggal "Earthquake Resistant Design of Structures" vol. 4 C Oxford University Press, ISBN10: 0-19-568817-1

[10] Bowles.J.E-“ Foundation Analysis and Design”, McGraw-Hill,Singapore-1974

[11] IS: 456-2000, "Code of Practice for Plain and Reinforced Concrete", Bureau of Indian Standards, New Delhi, India.

[12] IS:1893 (Part 1)-2002 Criteria for Earthquake Resistant Design of Structures, part 1-General provisions and buildings, fifth revision, Bureau of Indian Standards, New Delhi, India

\section{BIOGRAPHIES}

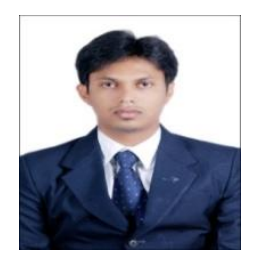

Naveen B S, Received the B.E Degree in Civil engineering from B.I.E.T College, Davanagere, and Visvesvaraya Technological University in 2010 and the M.Tech Degree in CADSS from UBDTCE, Davanagere in 2012.

Presently working as Assistant Professor in RK University, Rajkot, Gujarat, India, Email: bilichod.naveen@gmail.com naveenbilichod06@gmail.com

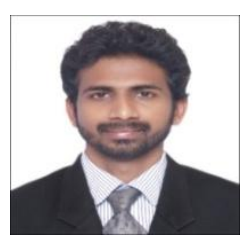

Parikshith Shetty, Received the B.E Degree in Civil engineering from B.I.E.T College, Davanagere, and Visvesvaraya Technological University in 2009 and the M.Tech Degree in Structural Engineering from KLE Society College of Engineering and Technology, Belagavi in 2011.

Presently working as Structural Engineer in Frames Group of Energy system, Pune, Maharashtra, India

Email: parikshithshetty@yahoo.com parikshithcpl@gmali.com

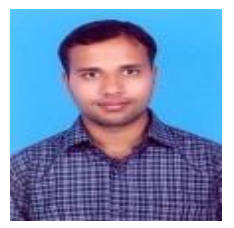

Naveen Kumar, Received the B.E Degree in Civil Engineering from B.I.E.T College Davanagere, Visveswaraya Technological University in 2009 and the M Tech Degree in CADSS from UBDTCE, Davanagere in 2012.

Presently working as Assistant Professor in GMIT College, Davanagere, Karnataka, India.

Email:naveensoppy@gmail.com 